\title{
The Impact of Franchisor's Economic and Philanthropic CSR on Franchisees' Economic Satisfaction, Social Satisfaction, and Loyalty
}

$$
\begin{gathered}
\text { 프랜차이즈 본부의 경제적 책임과 박 애주의적 책임이 가맹점의 경제적 만족, } \\
\text { 사회적 만족, 그리고 충성도에 미치는 영향* }
\end{gathered}
$$

Soon-Beom HUR(허순범) ${ }^{* *}$, Yong-Sook NOR(노용숙) ${ }^{* * *}$, Debora LEE(이드보라) ${ }^{* * * *}$

Received: August 20 2019. Revised: September 03 2019. Accepted: September 10, 2019.

\section{Abstract}

Purpose - The major objective of this study was to investigate the effect of franchisor's (economic and philanthropic) CSR in inspiring franchisee's loyalty for the franchisor. Another aim of this investigation also was to clarify the mediating role of economic and social satisfaction in the relationship between franchisor's CSR and franchisee's loyalty.

Research design, data, and methodology - This study explores the structural relationship between franchisor's CSR and franchisee's loyalty and in these relationships, the mediating role of relationship satisfaction. Data were gathered from employees(above manager) in food-service franchisee companies in Seoul, Korea. The questionnaires were distributed to managers of the franchise stores. A total of 251 questionnaires were collected. Data management and analysis were performed using SPSS 21.0 and SmartPLS 3.0. Evaluation of measurement model and structural model was carried out using confirmatory factor analysis and correlation analysis.

Result - The results of this study show as follows. First, economic CSR had positive effects on economic satisfaction and social satisfaction. Second, philanthropic CSR had positive effects on social satisfaction. Third, economic satisfaction and social satisfaction had positive effects on franchisee's loyalty to the franchisor.

Conclusions - The important implications of this study have as follows. First, this study has found that economic CSR can create a high economic satisfaction and social satisfaction of franchisee. Second, this findings suggest that the philanthropic CSR can improve the social satisfaction of franchisee. Third, this results demonstrate, for the first time, that the economic satisfaction and social satisfaction of franchisees can play a crucial role to improve their loyalty for the franchisor and pursue mutual development by maintaining the stable business relationship with a franchisor. In this investigation there are at least three limitations. First, Because the research sample is limited to the foodservice franchisee in Seoul, it is not possible to be representativeness of the national franchisee. Second, CSR activities are mostly focused on large franchise companies. Therefore, there is a limit to the research approach. Finally, this study examined the effect of economic CSR and philanthropic CSR on the loyalty of franchisors, but in the future study, it is necessary to analyze the relationship between CSR and loyalty of franchise companies by collecting specific quantitative data such as re-contract rate and management performance of franchisees.

Keywords: Economic CSR, Philanthropic CSR, Economic Satisfaction, Social Satisfaction, Loyalty, Franchise.

JEL Classifications: L83, M50, M54.

* This paper was presented at the 2019 Spring Conference of the Korean Society for Franchise Management and revised and supplemented.

* First Author, CEO, Small Big Consulting, Gyeonggi Province, Korea. Tel: +82-31-551-1881, Email: gosbhur98@gmail.com

** Co-author, CEO, Association Board of Korean Education Evaluation, 33, Songpa-daero 34-gil, Songpa-gu, Seoul 138-854, South Korea. Tel: +82-2-2202-8100, Email: w8100@hanmail.net

${ }^{* * * *}$ Corresponding Author, Doctoral Student, Department of Hotel \& Restaurant Management, Auburn University, Auburn, AL, USA.

Tel: +1-770-7420-1103, Email: dzl0054@tigermail.auburn.edu 


\section{1. 서론}

영향력이 커지면 그만큼 책임도 커진다. 1979년 대처리즘 (Thatcherism)으로부터 시작된 신자유주의 체제는 대기업의 영향력을 증대시 켰다. 대기업의 영향력이 증대 함에 따라 그에 대응하는 기업의 사회적 책임(Corporate Social Responsibility, CSR)의 수행에 대한 요구도 높아지고 있다. 한국 국내 총생 산(GDP)에서 자산 상위 30 대 재벌(공기업 집단 제외)이 차 지하는 비중은 1987 년 $55.30 \%$ 에서 2016년 $100.31 \%$ 로 증 대했다(Wi, 2018). 주요 대기업에서는 기업의 사회적 책임에 대한 요구에 부 응하기 위해 취약 계층지원, 환경보전, 문화예 술 및 교육, 의료 보건 등 다양한 분야별 활동을 하고 있다. 매출액 기준 500대 기업 중 194개사가 2017년 한 해 동안 지출한 사회공헌지출액 규모는 총 2 조 7,243 억 원으로 증가 했다. 또한, 매출액 대비 사회공 헌지출비율은 2016년 0.15\% 에서 2017 년 $0.18 \%$ 로 증가하였으며, 임직원 봉사 활동 참 여율도 평균 $50 \%$ 이상으로 1 인당 평균 봉사 활동시간은 8 시간으로 조사되었다(FKI, 2018). 이는 기업에 대한 이해 관 계자의 요구가 다양해짐에 따라 기업이 CSR 프로그램을 분 야별로 다양하게 마련하여 운영하고 있고, 기업 임직원도 $\mathrm{CSR}$ 의 중요성과 필요성을 인식하고 있음을 보여준다.

한편, 국내 프랜차이즈 산업은 자영업 창업과 고용창출의 일익을 담당하며 지속적인 성장세를 유지하고 있다. 프랜차 이즈 산업의 2017년 매출 (가맹본부와 가맹점)은 전년 대비 $2.7 \%$ 증가한 119.7 조 원으로, 우리나라 명목 $\operatorname{GDP}(1,730$ 조 원)의 $6.9 \%$ 를 차지 했으며, 고용은 전년 대비 $11 \%$ 증가한 125.6 만 명으로 우리나라 경제활동인구(2,775만 명)의 $4.5 \%$ 를 차지했다. 그러나 이러한 프랜차이즈 산업의 성장에 따른 부작용도 발생 했다. 가맹점의 $15.3 \%$ 가 가맹본부와 불공정 거래 경험이 있고, 상호신뢰 수준은 가맹본부는 가맹점과 신 뢰 관계(68.6\%) 및 소통 수준(77.3\%)이 강하게 형성되어 있 다고 보는 데 반해, 가맹점은 신뢰 관계(33.7\%)와 소통 수준 $(39.8 \%)$ 이 저조한 것으로 평가하여 가맹사업자 간 명 확한 견해 차이가 확인됐다(Ministry of Trade, Industry and Energy, 2019). 이는 프랜차이즈 산업이 빠르게 성장하고 영 향력은 증대 됨에 따라 이해 관계자들의 사회적 책임에 대한 다양한 요구가 증가하고 있어 프랜차이즈 산업에서 CSR 활 동에 대한 연구와 실 천이 필요하다는 것을 시사한다. 이러한 사회적 요구에 부 응하기 위하여 프랜차이즈 기업들도 브랜 드 이미지 개선을 통해 경영성과를 제고하고자 다양한 CSR 활동을 진행하고 있지만 아직은 효과가 적은 수준이다(Lee et al., 2010).

치열한 경쟁 환경에서는 CSR 활동의 중요성이 커질 수 있다(Kim \& Cho, 2014). 왜냐하면, 소비자는 적 극적으로 기 부나 자선활동을 하는 기업에 긍정적인 평가를 하고 같은 가격일 경우 사회적 책임을 다하는 착한 기업의 제 품이나 서비스를 구매하는 것으로 나타났기 때문이다(Barone et al., 2000). 또한, 프랜차이즈 기업의 경우 가맹본부의 비 윤리적 인 행위로 인해 사회적 책임을 다하지 못하는 기업이라는 인식을 가맹점에 심어준다면, 브랜드에 대한 부정적 이미지 를 형성하게 되고 낮은 충성도를 갖게 된다 (Lim \& Kwon, 2017). 프랜차이즈 본부의 성공 요인은 가맹점의 만족을 통
한 장기적 관계를 유지하는 것이다. 가맹점과의 관계는 가맹 본부의 이미지에 따라 달라질 수 있어 가맹본부는 CSR 활 동으로 기업 이미지를 제고하여 가맹본부와 가맹점간의 장 기적 관계를 형성하는 것이 중요하다(Han \& Yu, 2010; Lim \& kwon, 2017).

그러나 지 금까지 기존 연구들은 소비자의 CSR 인식이 기 업의 평판과 이미지를 개선시키고 결과적으로 경영성과와 시장에서 기업의 지위를 높여주며, 소비자의 제 품에 대한 태 도, 만족 및 충성도에 긍정적인 영향을 미치는지를 살펴보았 다(Brown \& Dacin, 1997; Forehand \& Grier, 2003; Bhattacharya \& Sen, 2004; Hur \& Choi, 2014). 또한, 종업 원의 CSR 활동에 대한 인식은 조직 신뢰 (Lin, 2010; Vlachos et al., 2010; Hansen et al., 2011; Farooq et al., 2014), 조직 자부심(Jones, 2010), 조직 동일시(Jones, 2010; Farooq et al., 2014) 등을 매개로 조직에 대한 긍정적인 태 도와 행동을 증가시키고, 조직몰입, 직무 만족, 충성 의도에 긍정적인 영향을 미치기도 한다는 연구들이 주로 이 루어졌 다(Peterson, 2004; Brammer et al., 2007; Valentine \& Fleischman, 2008; Turker, 2009; Vlachos et al., 2010; Stites \& Michael, 2011; Farooq et al., 2014; Choi et al., 2017; Kim, 2018). 따라서 개인 수준의 차원에서 소비자와 종업원의 CSR 인식은 긍정적인 경영성과를 창출하는 것은 물론 기업 내부적으로도 긍정적인 영향을 미치는 것으로 판 단할 수 있다.

따라서 $\mathrm{B} 2 \mathrm{~B}$ 마케팅 관점에서 $\mathrm{CSR}$ 이 이해 관계자들과의 장기적인 관계 유지를 위한 마케팅 활동으로 인식되고 있음 (Balmer \& Greysner, 2006; Han \& Lee, 2016)에도 불구하 고 프랜차이즈 가맹본부와 가맹점간의 관계마케팅 차원에서 의 CSR 연구는 미 흡했다. 이런 관점에서 본 연구는 프랜차 이즈 가맹본부의 경제적 CSR과 박애주의적 CSR을 선행변 수로 제시하여 가맹점의 경제적 만족과 사회적 만족에 미치 는 영향을 고 찰하고자 한다. 또한, 경제적 만족과 사회적 만 족의 결과로 충성도를 제시하여 가맹본부의 CSR 활동이 경 제적 만족과 사회적 만족을 매개로 가맹점의 충성도에 어 떠 한 영향을 미치는지를 확인하고자 한다(Figure 1 참고). 마지 막으로, 본 연구의 결과를 토대로 프랜차이즈 본부의 CSR 활동이 가맹점의 긍정적인 감성적, 행동적 반 응을 가 져올 수 있음을 규명하여 향 후 연구에 대한 제언과 프랜차이즈 기업 의 관리자들을 위한 실 무적 시사점을 제시하고 한다.

\section{2. 이론적 고찰}

\section{1. 기업의 사회적 책임}

기업의 사회적 책임은 기업이 사회에 대해 부 담하는 의 무 (social obligation)로 우리 사회의 목적과 가치에 맞는 정 책을 추구하거나 그러한 의사결정을 하거나, 행동노선을 수행할 기업인의 의 무를 의미하며 "공공책임(public responsibility)", "사회적 의 무(social obligation)", 그리고 "기업 도 덕성(business morality)"으로 개 념화했다(Bowen, 1953). 이러한 기업의 사 회적 책임에 대한 사회적 의 무로의 개 념화는 여러 연구자에 
의해 받아들여져 왔다(Brown \& Dacin, 1997; Carroll, 1979). 또한 Carroll(1979, 1991)은 이러한 기업의 책임을 좀 더 구 체적인 네 가지 유형 즉, 경제적 책임, 법적 책임, 윤리적 책임, 그리고 박애주의적 책임으로 분 류하고 이를 피라미드 구조로 제시하였다. 첫 번째 피라미드 단인 경제적 책임은 $\mathrm{CSR}$ 의 가장 기초적인 토대로 주주의 경제적 수 익을 극대화 하고, 타 기업과의 경쟁에서 강한 우위를 유지하며, 운영 효 율성을 높은 수준으로 유지하여 지속적으로 이 윤을 창출하 는 것을 말한다. 두 번째 피라미드 단인 법적 책임은 정부의 법과 규칙을 준수하여 상 품과 서비스를 공 급하는 준 법적인 기업 시 민이 되어야 함을 강조한다. 세 번째 피라미드 단인 윤리적 책임은 기업의 목표를 달성하기 위해 윤리 규범과 타협하지 않고 착한 기업 시 민으로 사회적 관습과 윤리 규 범의 기대에 부응하여 기업을 운영해야 할 책임을 강조한다. 피라미드 최상 층에 위치한 박애주의적 책임은 사회의 박애 주의적, 자선적 기대에 부응하여 순수 예 술이나 공연 예 술을 지원하거나 공공 교육기관을 지원하여 지역 커뮤니티에서 경영자와 종업원들이 자선 활동에 참여하여 지역사회의 “삶 의 질"을 향상시키는 활동을 말한다.

$\mathrm{CSR}$ 활동은 해 당 기업 이미지 개선과 소비자의 제품에 대한 긍정적인 태도 및 충성도에 영향을 미치는 선행 변수다 (Brown \& Dacin, 1997; Bhattacharya \& Sen, 2004; Forehand \& Grier, 2003; Choi et al., 2009; Park et al., 2012). 또한, 프랜차이즈 본부의 CSR 활동이 가맹점의 경제 적 만족과 재계약 의도에 영향을 미 친다(Shin et al., 2000; Lim \& Kwon, 2017).

Carroll(1979, 1991)이 분 류한 4가지 차원은 외부 이해 관 계자가 기업이 법을 준수하고, 윤리적으로 올바르게 경영하 는가를 분명하게 인식하기가 힘들며, 내부 구성원들조차 구 분 지어 인지하는 데 한계가 있다(Lee \& Choi, 2010; Hur et al., 2014; Hur \& Choi, 2014). 이에 본 연구에서는 선행 연구를 토대로 CSR 활동을 가맹점이 인식할 수 있는 2가지 차원 즉, 프랜차이즈 가맹점이 인지할 수 있는 경제적 책임 과 외부적 CSR 활동인 박애주의적 책임으로 분류했다.

\subsection{1. 경제적 책임}

경제적 책임은 주주의 경제적 수 익을 극대화하고, 타 기 업과의 경쟁에서 강한 우위를 유지하며, 운영 효율성을 높은 수준으로 유지하여 지속적으로 이 윤을 창출하는 것을 말한 다(Carroll, 1979, 1991). 또한, 기업은 국 민경제의 경제주체 (국가, 기업, 가계) 중 기본적인 경제단위로서 재화와 서비스 를 생산하고 공 급하는 과정을 통해 이 윤을 극대화하고 고용 을 창출해야 하는 책임을 가지고 있으며, 이러한 기업의 경 제적 책임 활동은 기업의 경제적 차원의 투자수익률, 총자산 이익률, 수익성장률에 긍정적인 영향을 미 친다(Maignan et al., 1999; Maignan \& Forrell, 2001; Park et al., 2015).

프랜차이즈 가맹본부는 가맹점과의 관계 형성과 유지에 대한 의사결정을 할 때, 거래비용이론(transaction cost theory)에 기초하여 의사결정을 한다(Huo, 2012). 거래비용 이론은 기업이 조직을 구성할 때 내부조직과 외부조직을 통 한 각각의 거래비용을 비 교하여 상대적으로 효율성이 높은
조직을 구성한다는 것이다 (Coase, 1937). 즉 기업은 경제적 효익을 위한 노력을 지속하며 효율적인 거래 관계를 형성하 고자 노력하고, 거래 관계를 계속 유지할지 여부는 경제적 이익과 비용을 비 교하여 결정하기 때문에 프랜차이즈 가맹 본부의 경제적 책임 활동은 가맹점과의 관계를 유지하는데 중요한 요인으로 보인다.

Luo and Bhattacharya(2006)는 CSR 활동과 시장가치와 의 관계에 관한 연구에서 CSR 활동은 고 객만족도를 향상시 키고 그 결과로 시장가치도 제고하는 것으로 나타났다. 또 한, 경제적 책임 활동은 조직에 대한 종업원들의 신뢰를 제 고하고 이직 의도를 감소시킨다(Lee et al., 2012). Weber (2008)는 기업의 사회적 책임 활동이 수익창출에 도 움이 되 며 브랜드 가치의 향상에도 긍정적인 영향을 줄 수 있다고 하였다. 따라서 본 연구에서 경제적 책임은 가맹점이 지각하 는 가맹점에 대한 가맹본부의 수 익창출을 위한 노력의 정도 로 정의되 었다.

\subsection{2. 박애주의적 책임}

박애주의적 책임은 사회의 박애주의적, 자선적 기대에 부 응하여 순수 예 술이나 공연 예 술을 지원하거나 공공 교육기 관을 지원하여 지역 커뮤니티에서 경영자와 종업원들이 자 선 활동에 참여하여 지역사회의 “삶의 질”을 향상시키는 자 율적 활동을 말한다. 지역사회의 발전을 중요시하는 기업의 박애주의적 책임 활동은 해당 기업의 제품 신뢰에 긍정적인 영향을 주며, 종업원의 몰입에 유의한 영향을 준다(Maignan et al., 1999; Maignan \& Forrell, 2001; Pivato et al., 2008; Lee et al., 2012). 또한, 종업원들의 지역사회에 대한 박애 주의적 책임 활동은 소비자들로 하여금 해당 기업의 긍정적 인 이미지 형성에 영향을 준다 (Hess et al., 2002; Park et al., 2014).

프랜차이즈 시스 템은 가맹본부와 가맹점간의 계약을 기반 으로 이 루어지는 공생관계다. 가맹본부는 가맹점에 대하여 가맹본부의 제 품과 서비스, 경영 노하우, 그리고 상호와 상 표(브랜드) 사용권리 등을 제공하고 가맹점은 그에 대한 대 가로 가맹비와 로 열티를 지 급한다(Hur et al., 2018; Kim, 2018). 가맹점은 가맹본부의 상표(브랜드)를 사용하기 때문 에 가맹본부의 브랜드 이미지는 가맹점의 경영성과에 영향 을 미치고, 이는 결과적으로 가맹점이 가맹본부와 재계약 여 부를 결정하는 데 중요한 영향을 미친다(Lim \& Kwon, 2014). 따라서 프랜차이즈 기업의 경우 가맹본부가 사회의 기대에 못 미치는 비윤리적인 행동을 하여 소비자들로부터 사회적으로 책임 있는 경영 활동을 하지 못하는 기업으로 인식된다면, 브랜드 이미지에 부정적인 영향을 주게 되어 가 맹점과의 장기지향성에 부정적인 영향을 미 친다(Lim, 2015).

Mohr and $\mathrm{Webb}(2005)$ 은 기업의 사회적 책임 활동과 고 객의 반 응과의 관계에 관한 연구에서, 고객들은 사회적 책임 활동(박애주의적 책임, 환경적 책임)을 위해 노력하는 기업 에 대해 우호적인 태도를 지니며, 제품을 선 택할 때 사회적 책임 활동을 수행하지 않는 기업의 제 품보다 사회적 책임 활동을 수행하는 기업의 제 품을 더 선호하는 것으로 나타났 다. 따라서 본 연구에서 박애주의적 만족은 가맹본부가 이해 
관계자들을 대상으로 자선활동 수행 정도나 지역사회에 대 한 기여도로 정의되었다.

\section{2. 관계 만족}

관계 만족은 특정 경로 구성원이 상대방 기업과의 업무 관계에 대한 모든 측면에서 평가한 결과 갖게 되는 긍정적 인 정서적 상 태로 정의된다(Anderson \& Narus, 1990; Dwyer \& Oh, 1987; Ganesan, 1994; Abdul-Muhmin, 2005). 관계 만족은 장기적인 익을 위해 상호 협력을 촉진하고, 거래 관계를 지속시키는 데 효과가 있다고 할 수 있다 (Ganesan, 1994; Hur et al., 2018). 그리고 만족은 기업과 거래 파트너 또는 개인 간의 충성도, 신뢰, 그리고 장기지향 성에 영향을 미 친다 하였다(Abdul-Muhmin, 2005; Anderson \& Narus, 1990).

경로 구성원 간의 관계 만족은 거래 상대방과의 관계에서 경제적인 면을 강조하는 경제적 만족과 비경제적인 면을 강 조하는 비경제적 만족으로 구분할 수 있으며(Gassenheimer \& Ramsey, 1994; Geyskens et al., 1999), 또한 매출, 이윤, 할인 등 거래 상대방과의 관계로부터 유입되는 경제적 성과에 대한 경로 구성원의 평가를 의미하는 경제적 만족과 충만감, 기쁨, 친근감 등 교환 상대방과의 상호작용 관계에 관한 경로 구성원의 심리·사회적 측면에서의 평가를 의미하는 사회적 만 족으로 구분하여 정의된다(Geyskens \& Steenkamp, 2000).

\subsection{1. 경제적 만족}

경제적 만족은 유통경로 구성원이 거래 상대방과의 관계 로부터 발생하는 매출, 이윤, 할인 등 경제적 산출에 대한 평가결과를 말한다(Geyskens \& Steenkamp, 2000). 즉 가맹 점이 가맹본부와 관계에서 발생하는 매출, 이윤, 할인 등 경 제적 성과에 대한 긍정적인 평가결과를 말한다. 가맹본부가 수행하는 가맹점에 대한 각종 마케팅 지원은 가맹점에서 본 경제적 성과(economic outcome)를 증가시키게 되고, 그 결 과로 가맹점의 경제적 만족도를 높여 줄 수 있다 $(\mathrm{Kim}$, 2007). 따라서 본 연구에서는 경제적 만족을 가맹점이 가맹 본부와의 관계로 발생한 재무적인 성과와 마케팅 활동에 대 해 지각하는 결과에 대한 평가로 정의되었다.

\subsection{2. 사회적 만족}

사회적 만족은 유통경로 구성원이 거래 상대방과의 관계 에서 충만감, 기쁨, 친근감 등 교환 상대방과의 상호작용 관 계에 관한 경로 구성원의 사회 심리적 측면에서의 평가로 정의된다(Geyskens \& Steenkamp, 2000). 좀 더 사회적 관 점에서의 사회적 만족은 상호작용 경험의 평가로 정의된다 (Crosby et al., 1990; Scheer \& Stern, 1992). 또한, 사회적 관계의 성과에 만족한 경로 구성원은 거래 상대방과 관계를 맺고, 함께 일하는 것에 감사한다(Geyskens et al., 1999).

$\mathrm{Yu}$ and $\mathrm{Han}$ (2009)은 유통경로 구성원 간의 장기적 관계 를 구축하는 데에는 비강압적인 마케팅 전략과 함께 단기적 인 경제적 만족보다 좀 더 인간적이고 사회적인 관계에서
비롯된 비경제적(사회적) 만족이 더 중요한 선행요인이라고 주장했다. 따라서 본 연구에서는 사회적 만족을 가맹점이 가 맹본부와의 상호작용 관계에서 느끼는 우호적이고 존중하려 는 심리적 감정에 대한 평가로 정의되 었다.

\section{3. 충성도}

충성도는 기업 간 거래에서 호의적인 태도와 고 객유지를 통해 장기적인 거래 관계를 유지하는 데 필요한 가장 중요 한 요소다(Dwyer et al., 1987; Fornell, 1992; Biong, 1993). 기업에 대한 거래적인 애착뿐만 아니라 감정적인 애착을 반 영하는 것으로 제 품이나 서비스에 대한 경험에 만족한 고 객 이 특정 제 품 및 서비스에 대한 지속적인 구매 의도나 추천 하려고 하는 의도를 의미한다(Hoffman \& Bateson, 2011; $\mathrm{Ha}$ et al., 2016; Kim, 2018). 또한, 충성도는 과거의 구매 결정이 현 재 구매 결정에 영향을 미치는 수단이 된다 (Bubb \& Van Rest, 1973). 충성도가 높다는 것은 특정상품이나 서 비스를 계속하여 거래 또는 구매하려는 의도와 태도를 견지 하는 것이라고 할 수 있으며, 이는 가맹본부에 대한 가맹점 의 충성도가 높을수록 가맹본부와 계약관계를 계속 유지하 려고 할 것이고, 예비 가맹점주에게 현 재 계약관계의 가맹본 부를 호의적으로 추천할 것이다.

따라서 본 연구에서는 충성도를 가맹점이 미래의 잠재적 가맹점주에게 현 재 계약관계에 있는 가맹본부를 우호적으로 추천하려는 의도와 현 재의 가맹본부와 계약 종 료 시 재계약 을 하려는 의도로 정의되었다.

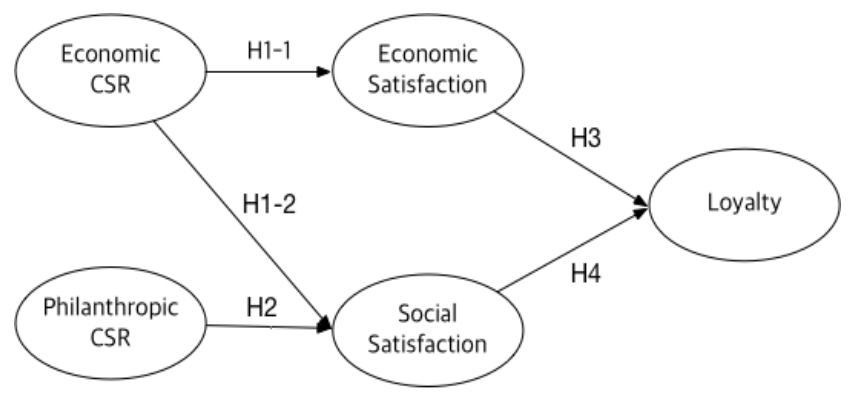

Figure1: Proposed model

3. 연구설계

\section{1. 연구가설}

3.1.1. 경제적 책임과 박애주의적 책임이 경제적 만족, 사회 적 만족에 미치는 영향

기업의 사회적 책임 활동은 고객만족도를 높이고(Luo \& Bhattacharya, 2006), 조직 신뢰를 매개로 경제적 책임 활동 과 박애주의적 책임 활동은 직무 만족에 유의한 정의 영향 관계가 있음을 보여줬다(Lee et al., 2012). 경제적 책임 활 동은 경제적 성과에 긍정적인 영향을 미치고, 박애주의적 책 
임 활동은 종업원의 몰입, 제품 신뢰, 그리고 기업 이미지 형성에 유의한 정의 영향을 미치는 것으로 나타났다 (Maignan \& Fell, 1999, 2001; Pivato et al., 2008; Hess et al., 2002; Park et al., 2014). 또한, 기업의 사회적 책임 활 동은 소비자 동일시(consumer identification)를 통해 해 당 기 업에 호의적인 태도와 평가로 이어지고, 동일시된 소비자는 해당 기업의 제공물에 만족할 가 능성이 높게 나타난다 (Bhattacharya et al., 1995; Bhattacharya \& Sen, 2003; Brown \& Dacin, 1997; Sen \& Bhattacharya, 2001; Luo \& Bhattacharya, 2006).

따라서 본 연구에서는 경제적 책임과 경제적·사회적 만족 의 관계를 다음과 같은 가 설로 제시하였다.

$\mathrm{H1}$ : 가맹본부의 경제적 책임은 가맹점의 경제적 만족, 사 회적 만족에 정 $(+)$ 의 영향을 미칠 것이다.

H1-1: 가맹본부의 경제적 책임은 가맹점의 경제적 만족 에 정 $(+)$ 의 영향을 미 칠 것이다.

H1-2: 가맹본부의 경제적 책임은 가맹점의 사회적 만족 에 정 $(+)$ 의 영향을 미 칠 것이다.

H2: 가맹본부의 박애주의적 책임은 가맹점의 사회적 만족 에 정 $(+)$ 의 영향을 미칠 것이다.

\subsection{2. 경제적 만족과 사회적 만족이 충성도에 미치는 영향}

특정 기업에 만족한 고 객은 해 당 기업에 대한 충성심이 크고(Bolton \& Drew, 1991; Oliver, 1980), 긍정적인 구전을 하며(Szymanski \& Henard, 2001), 기꺼이 높은 가 격을 지불 하려고 한다(Homburg et al., 2005). 또한, 기업이 고 객에 대 한 만족도를 높이면 높일수록 시장가치가 증가하고 현금흐 름(cash flow) 수준도 높게 형성될 수 있는 것으로 나타났다 (Gruca \& Rego, 2005; Fornell, 1992; Mittal et al., 2005; Luo \& Bhattacharya, 2006). Dwyer et al.(1987)은 기업 간 교환이 단속적 거래가 아 닌 교환적 관계로 지속적으로 유지 되기 위해서는 경제적 만족과 사회적 만족이 선행되는 것이 중요한 것으로 나타났다. 또한, 사회적 관계의 성과에 만족 한 경로 구성원은 거래 상대방과 관계를 맺고, 함께 일하는 것에 감사한다(Geyskens et al., 1999). 프랜차이즈 가맹본 부의 사회적 책임 활동은 가맹본부의 이미지를 제고하고, 가맹 본부의 브랜드 이미지가 높아지면 고 객의 만족도 또한 높아져 가맹점의 경제적 성과도 높아지고, 가맹점의 재계약에 대한 긍 정적인 태도를 보이는 것으로 나타났다(Lim \& Kwon, 2017).

따라서 본 연구에서는 다음과 같은 가 설을 제시하였다.

H3: 가맹점의 경제적 만족은 충성도에 정 (+)의 영향을 미 칠 것이다.

H4: 가맹점의 사회적 만족은 충성도에 정 $(+)$ 의 영향을 미 칠 것이다.

\section{2. 변수의 측정}

본 연구에서는 설문지를 사용하여 연구 모형과 설정된 가
설을 검증하였다. 설문지에 사용된 모든 항목은 7점 리 커트 척도 "1점=전혀 그렇지 않다"에서 "7점=매우 그 렇다"로 측정 되었다.

먼저, 기업의 사회적 책임은 경제적 책임(7개 항목)과 박 애주의적 책임( 5 개 항목) 두 가지 하위차원으로 측정되었다 (Carroll, 1979, 1991; Corson \& Steiner, 1974; Lee et al., 2009; Ostlund, 1977; Lee et al., 2012). 경제적 만족은 가 맹점이 가맹본부와의 관계로 발생한 재무적인 성과와 마케 팅 활동에 대해 지각하는 결과에 대한 평가를 측정하기 위 해 5 개 항목으로 측정되었고 사회적 만족은 가맹점이 가맹 본부와의 상호작용 관계에서 느끼는 우호적이고 존중하려는 심리적 감정에 대한 평가를 측정하기 위해 5 개 항목으로 측 정되었다(Oliver, 1980; Gassenheimer et al., 1996; Geyskens \& Steenkamp, 2000). 그리고 충성도는 재계약 의 도와 추천 의도로 측정되었다. 재계약 의도는 현 재의 가맹본 부와 계약 종료 시 재계약 의도를 측정하기 위해 2개 항목 으로 측정되었다(Lewis \& Lambert, 1991; Ganesan, 1994; Kang et al., 2006). 추천 의도는 가맹점이 미래의 잠재적 가맹점주에게 현 재 계약관계에 있는 가맹본부를 우호적으로 추천 의도를 측정하기 위해 2개 항목으로 측정되었다(Brown et al., 2005).

\section{3. 표본설계 및 분석방법}

본 연구에서는 연구가설 검증을 위하여 외식 프랜차이즈 가맹점(서울지역)에서 근 무하고 있는 직원(매니저급 이상)을 대상으로 2018년 5월 1일부터 5월 30일까지 설문 조사를 시행하였으며, 총 251 개의 표본이 회수되어 분 석에 활용하 였다.

또한, 수집된 자 료를 분 석하기 위하여 SPSS 21.0과 SmartPLS 3.0 프로그램을 이용하였다. 조사대상자의 일반적 특성을 빈도분석으로 파악하였고, 모형 적합도를 검정하기 위해 신뢰도와 타 당도, 확인적 요인분석 및 상관관계 분석 등이 진행된 후 제안된 연구모형 검증을 위해 구조모형분석 (Structural Equation Modeling, SEM)을 시행하였다.

\section{4. 실증분석}

\section{1. 표본의 일반적 특성}

본 연구의 응답자 251 명의 일반적 특성은 <Table 1>과 같다. 먼저, 성별은 남자 $(73.7 \%)$ 가 대부분을 차지하였다. 연 령은 40 대 $(48.2 \%)$ 가 가장 많았고, 다음으로 30 대(27.9\%), 50 대 $(12.7 \%)$ 의 순으로 나타났다. 학력은 4 년제 졸업(39.0\%) 이 다음으로 고 졸(34.7\%), 전문대졸(23.5\%)의 순이었다. 종 업원 수는 4 5명 이하 (31.1\%), 6 9명 이하(28.3\%), 3명 이 하(27.5\%), 그리고 10 명 이상(13.1\%)의 순으로 나타났다. 가 맹본부와 가맹점과 가맹거래 기간은 2 년 미만이 전체의 $61.0 \%$ 를 차지하는 것으로 나타났다. 
Table 1: Respondent's profiles $(n=251)$

\begin{tabular}{|c|c|c|c|}
\hline & & Frequency(n) & $\%$ \\
\hline \multirow{3}{*}{ Gender } & Male & 185 & 73.7 \\
\cline { 2 - 4 } & Female & 66 & 26.3 \\
\hline \multirow{4}{*}{ Age } & $20-29$ & 22 & 8.8 \\
\cline { 2 - 4 } & $30-39$ & 70 & 27.9 \\
\cline { 2 - 4 } & $40-49$ & 121 & 48.2 \\
\cline { 2 - 4 } & over 50 & 32 & 12.7 \\
\hline \multirow{4}{*}{$\begin{array}{c}\text { Education } \\
\text { Level }\end{array}$} & High school & 87 & 34.7 \\
\cline { 2 - 4 } & Two-year college & 59 & 23.5 \\
\cline { 2 - 4 } & Completed university & 98 & 39.0 \\
\cline { 2 - 4 } & Graduate school or more & 6 & 2.4 \\
\hline \multirow{4}{*}{\begin{tabular}{c} 
Employees \\
\cline { 2 - 4 }
\end{tabular}} & under 3 & 69 & 27.5 \\
\cline { 2 - 4 } & $4-5$ & 78 & 31.1 \\
\cline { 2 - 4 } & 6-9 & 71 & 28.3 \\
\hline \multirow{3}{*}{$\begin{array}{c}\text { Duration of 10 } \\
\text { contract } \\
\text { (year) }\end{array}$} & Under 1 & 33 & 13.1 \\
\cline { 2 - 4 } & $1-$ under 2 & 69 & 27.5 \\
\cline { 2 - 4 } & $2-$ under 3 & 34 & 33.5 \\
\cline { 2 - 4 } & $3-$ under 4 & 21 & 13.1 \\
\cline { 2 - 4 } & Over 5 & 35 & 13.9 \\
\hline
\end{tabular}

\section{2. 측정 항목의 타당성 및 신뢰성 검증}

본 연구에서는 다항목으로 구성된 연구단위의 단일차원성 을 분 석하기 위하여 SmartPLS 3.0을 이용하였다(Hair et al., 2016; Park et al., 2016). 먼저, Cronbach's $\alpha$ 와 구성개념 신뢰도(Composite Reliability: CR)를 이용하여 연구대상의 내적 일 관성을 측정하는 신뢰성 분 석을 하였다. <Table 2> 에서와 같이, 경제적 책임, 박애주의적 책임, 경제적 만족, 사회적 만족, 그리고 충성도에 대한 Cronbach's $\alpha$ 값은 $.866-.944, \mathrm{CR}$ 값은 .903-.957로 요구 기준인 .70을 넘어 측정 항목 간 신뢰성이 있는 것으로 나타났다.

다음으로, 개념 타당성을 측정하기 위해 수 렴 타당성과 판별 타 당성으로 구분하여 검증하였다. 수렴 타당성은 동일 한 개 념 간의 높은 상 관관계로 평가되는데 <Table 2>에서와 같이, 각 요인에 적 재된 요인 적 재값은 .649 이상이며, AVE 값이 .609 이상으로 나타나 각 연구단위의 수 렴 타당성은 입증되었다.

Table 2: Measurement model

\begin{tabular}{|c|c|c|c|c|c|}
\hline Constructs and items & \begin{tabular}{c|} 
Factor \\
loadings
\end{tabular} & $\begin{array}{l}\text { Cronbach's } \\
\text { Alpha }\end{array}$ & rho_A & $\mathrm{CR}^{\mathrm{a}}$ & $\mathrm{AVE}^{\mathrm{b}}$ \\
\hline Economic CSR & & .896 & .935 & .915 & 609 \\
\hline My Franchisor has procedures in place to respond to complaint from every customer (including franchisees) & .769 & & & & \\
\hline My Franchisor strives to continuously improve the quality of the products(menu, food and beverage). & .773 & & & & \\
\hline My Franchisor places customer satisfaction first and implements policies related to its. & .821 & & & & \\
\hline My Franchisor has been successful at maximizing my profits. & 751 & & & & \\
\hline My Franchisor strive to lower my operating costs. & 649 & & & & \\
\hline My Franchisor closely monitor employee's productivity. & .839 & & & & \\
\hline Top management establishes long-term strategies for my business. & .843 & & & & \\
\hline Philanthropic CSR & & .905 & .911 & .929 & .725 \\
\hline My Franchior tries to help the poor. & .841 & & & & \\
\hline My Franchior tries to contribute toward bettering the local community. & .857 & & & & \\
\hline My Franchior tries to fulfill its social responsibility. & 881 & & & & \\
\hline My Franchior tries to accommodate governmental request. & .853 & & & & \\
\hline My Franchior tries to accommodate requests for NGOs. & .823 & & & & \\
\hline Economic Satisfaction & & .866 & .878 & .903 & 651 \\
\hline $\begin{array}{l}\text { After contracting with the franchisor at present, I feel that I am satisfied with the sales and } \\
\text { profitability of my franchise and have business feasibiltiy. }\end{array}$ & .817 & & & & \\
\hline $\begin{array}{l}\text { The product quality provided by the franchisor has greatly helped to increase the number of } \\
\text { customers, so I am satisfied with my decision to select the franchisor. }\end{array}$ & .741 & & & & \\
\hline The number of customers increased due to the thorough support system of my franchisor. & 829 & & & & \\
\hline The active marketing activities of my franchisor are very helpful in operating our franchisee. & .845 & & & & \\
\hline I am satisfied with the publicity and sales promotion activities supported by my franchisor. & .798 & & & & \\
\hline Social Satisfaction & & .867 & .883 & .904 & .654 \\
\hline The business relationship between my franchisor and the franchisee is friendly. & .801 & & & & \\
\hline My franchisor makes practical advice and criticism friendly for the operation of the franchisee. & 697 & & & & \\
\hline My franchisor respects the opinions of the franchisees. & .803 & & & & \\
\hline My franchisor tend to tell us everything we need to know about operating the franchisee. & .868 & & & & \\
\hline My franchisor kindly explains the background and reasons for the proposed management policy. & .862 & & & & \\
\hline Loyalty & & .944 & .955 & .957 & .817 \\
\hline When the contract with this franchisor expires, I will contract again. & .938 & & & & \\
\hline Even if other franchisors offer good terms, I will not switch to other franchisors. & 889 & & & & \\
\hline $\begin{array}{l}\text { Even if the contract with this franchisor expires, I will think of the current franchisor as a contracting } \\
\text { party prior to any other franchisors. }\end{array}$ & .904 & & & & \\
\hline I will tell others about the good points of this franchisor. & .910 & & & & \\
\hline I will recommend my current franchisor if others ask for advice to choose a franchisor. & .877 & & & & \\
\hline
\end{tabular}

${ }^{\mathrm{a} C R}$ : Composite reliability, ${ }^{\mathrm{b}} \mathrm{AVE}$ : Average variance extracted 
판별 타 당성은 상이한 개 념 간의 낮은 상관관계로 평가되 는데, <Table 3>에서와 같이 Fornell-Larcker 기준으로 검증 한 결과, $\mathrm{AVE}$ 값의 제 곱근 값이 상 관관계 계수 값보다 크 며, 쌍을 이룬 연구단위 간의 상 관관계 값의 자승 값이 AVE 값보다 작은 것으로 나타나 각 연구단위 간의 판별 타 당성 은 입증되 었다. 또한, 상관계수 값의 이 질성-단질성 특성 비 율을 나타내는 HTMT(the heterotrait-monotrait) 값을 살펴본 결과, .227-.696(p<.01)로 나타나 판별 타 당성은 입증되었다.

\section{3. 연구모형의 평가}

본 연구는 SmartPLS 3.0을 사용하여 연구 모형을 평가하 였다. PLS는 분산 설명력의 최대 화 또는 구조오차를 최소 화 하기 위한 연구에 적합한 분석 방법(Chin, 1998; Vinz et al., 2010; Park et al., 2016)으로 다음과 같이 평가되었다(Chin, 1998; Hulland, 1999; Tenenhaus et al., 2005; Hair et al., 2013; Park et al., 2016). 먼저, 설명력과 예 측적합도를 <Table 4>와 같이 평가하였다. 첫째, 다중공선성은 분산팽창 요인(variance inflation factor: VIF)을 구하여 진 단하는데 분 산팽창요인(variance inflation factor: VIF)이 5 보다 작아야 문 제가 없다. 본 연구에서는 1.000-1.668로 나타나 다중공선성 문제가 없는 것으로 나타났다. 둘째, 예측적합도 판정을 위 해 내생 변수의 설명력을 나타내는 결정계수인 $\mathrm{R}^{2}$ 값을 사용 하는데, 본 연구에서 $R^{2}$ 값은 경제적 만족이 0.141(14.1\%), 사회적 만족이 0.187(18.7\%), 그리고 충성도는 0.160(16.0\%) 로 Falk and Miller (1992)가 제시한 .100(10\%)보다 높게 나 타났다. Chin (1998)은 설명력 크기의 기준을 .67(강), .33(중), .19 (약)로 제시 하였다. 셋째, 예측적합도를 판단하기 위해 사용하는 내생변수의 중 복성을 나타내는 연구 단위 교차 타 당성의 중 복성(construct cross-validated redundancy; $\mathrm{Q}^{2}$ ) 값 은 0 보다 크면 예 측적합도가 있는 것으로 판단된다. 본 연구 에서는 경제적 만족이 .082 , 사회적 만족이 .108 , 그리고 충 성도는 . 118 로 나타나 예 측적합도의 기준을 충족시켰다.

Table 3: Fornell-Larcker criterion

\begin{tabular}{|c|c|c|c|c|c|}
\hline Item & $\mathbf{1}$ & $\mathbf{2}$ & $\mathbf{3}$ & $\mathbf{4}$ & $\mathbf{5}$ \\
\hline Economic CSR & .780 & & & & \\
\hline Philanthropic CSR & .633 & .851 & & & \\
\hline Economic satisfaction & .375 & .282 & .807 & & \\
\hline Social satisfaction & .408 & .368 & .577 & .809 & \\
\hline Loyalty & .567 & .190 & .374 & .331 & .904 \\
\hline
\end{tabular}

* Bold numbers indicate the square root of AVE

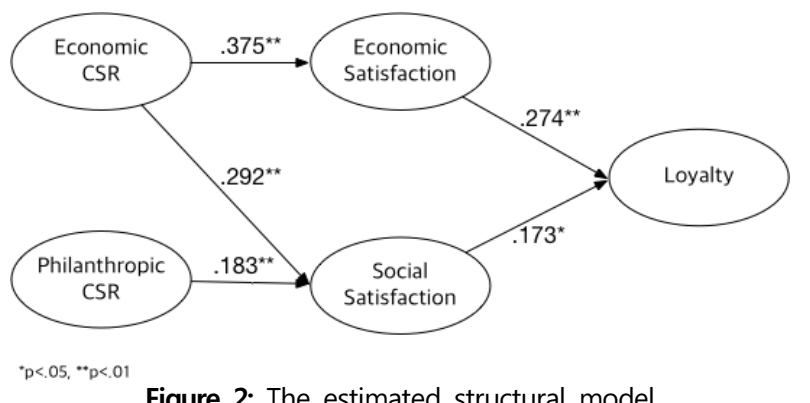

Figure 2: The estimated structural model

\section{5. 가설검정}

\section{1. 연구가설의 검증}

프랜차이즈 가맹본부의 기업의 사회적 책임(경제적 책임, 박애주의적 책임)이 가맹점의 경제적 만족, 사회적 만족, 그 리고 충성도에 미치는 구조적 관계를 검증한 결과는 <Table $4>$ 와 같다.

$\mathrm{H} 1$ 은 프랜차이즈 가맹본부의 경제적 책임이 가맹점의 경 제적 만족과 사회적 만족에 미치는 영향을 검증하기 위한 것이다. 검증 결과, 경제적 책임은 경제적 만족 $(\beta=.375$, $\mathrm{t}$-value $=6.696, p<.01)$ 과 사회적 만족 $(\beta=.292, \mathrm{t}$-value $=3.829$, $\mathrm{p}<.01)$ 에 유의한 정 $(+)$ 의 영향을 미치는 것으로 나타나, $\mathrm{H} 1-1, \mathrm{H} 1-2$ 는 지지가 되 었다.

$\mathrm{H} 2$ 는 프랜차이즈 가맹본부의 박애주의적 책임이 사회적 만족에 미치는 영향을 검증하기 위한 것으로, 검증 결과, 박 애주의적 책임이 사회적 만족에 정 $(+)$ 의 유의적 영향 $(\beta$ $=.183, \mathrm{t}$-value $=3.058, \mathrm{p}<.01)$ 을 미치는 것으로 나타나, $\mathrm{H} 2$ 는 지지되었다.

$\mathrm{H} 3$ 는 경제적 만족이 충성도에 미치는 영향을 검증하기 위한 것으로, 분석 결과, 경제적 만족은 충성도에 정 $(+)$ 의 유의적 영향 $(\beta=.274, \mathrm{t}$-value $=4.043, p<.01)$ 을 미치는 것으로 나타났다. 따라서 $\mathrm{H} 3$ 는 지지되 었다.

$\mathrm{H} 4$ 는 사회적 만족이 충성도에 미치는 영향을 검증하기 위한 것으로, 검증 결과, 사회적 만족이 충성도에 미치는 영 향은 정 $(+)$ 의 유의적 영향 $(\beta=.173, \mathrm{t}$-value $=2.105, \mathrm{p}<.05)$ 을 미치는 것으로 나타나, $\mathrm{H} 4$ 는 지지되 었다.

\section{2. 효과 크기 $\left(\mathrm{f}^{2}\right)$ 분석}

효과 크기 (effect size, fr) 분석은 종속 변수들에 대한 독립 변수들의 상대적 효과를 나타내며(Chin, 1998), 세 기준으로 분류( .02(소), .15(중), .35(대)) 된다(Cohen, 1988). <Table $4>$ 에서와 같이, 독립변수인 경제적 책임(.164)이 종속변수인 경제적 만족에 미치는 효과 크기는 중간이고, 종속변수 사회 적 만족을 설명하기 위한 독립변수 경제적 책임과 박애주의 적 책임의 효과 크기는 각각 .063과 .025로, 종속변수 사회 적 만족에 대한 독립변수 경제적 책임의 효과 크기는 중간 이하이고 박애주의적 책임은 작은 것으로 나타났다. 그리고 충성도에 대한 경제적 만족과 사회적 만족의 효과 크기는 각각 .060과 .024로 모두 중간 이하로 나타났다.

\section{6. 결론}

본 연구는 프랜차이즈 가맹본부의 사회적 책임 활동(경제 적 책임, 박애주의적 책임)이 경제적 만족과 사회적 만족을 매개로 충성도에 어 떠한 영향을 미치는가를 실증적으로 검 증하였다. 이러한 분 석 결과를 토대로 프랜차이즈 가맹본부 의 경제적 책임 활동과 박애주의적 책임 활동은 경제적 만 
Table 4: Standardized structural estimates

\begin{tabular}{|c|c|c|c|c|c|c|}
\hline \multicolumn{2}{|r|}{ Paths } & \multirow{2}{*}{$\begin{array}{c}\text { Estimate } \\
.375 \\
\end{array}$} & \multirow{2}{*}{$\begin{array}{c}t \text {-value } \\
6.696 \\
\end{array}$} & \multirow{2}{*}{$\begin{array}{c}\mathrm{p} \text {-value } \\
.000 \\
\end{array}$} & \multirow{2}{*}{$\begin{array}{c}\mathrm{f}^{2} \\
.164 \\
\end{array}$} & \multirow{2}{*}{$\begin{array}{c}\text { Results } \\
\text { Accepted }\end{array}$} \\
\hline $\mathrm{H} 1-1$ & Economic CSR $\rightarrow$ Economic satisfaction & & & & & \\
\hline $\mathrm{H} 1-2$ & Economic CSR $\rightarrow$ Social satisfaction & .292 & 3.829 & .000 & .063 & Accepted \\
\hline $\mathrm{H} 2$ & Philanthropic CSR $\rightarrow$ Social satisfaction & .183 & 3.058 & .002 & .025 & Accepted \\
\hline $\mathrm{H} 3$ & Economic satisfaction $\rightarrow$ Loyalty & .274 & 4.043 & .000 & .060 & Accepted \\
\hline $\mathrm{H} 4$ & Social satisfaction $\rightarrow$ Loyalty & .173 & 2.105 & .035 & .024 & Accepted \\
\hline & & \multicolumn{3}{|c|}{$R^{2}$} & \multicolumn{2}{|c|}{$\mathrm{Q}^{2}$} \\
\hline & Economic satisfaction & \multicolumn{3}{|c|}{.141} & \multicolumn{2}{|c|}{.082} \\
\hline & Social satisfaction & \multicolumn{3}{|c|}{.187} & \multicolumn{2}{|c|}{.108} \\
\hline & Loyalty & \multicolumn{3}{|c|}{.160} & \multicolumn{2}{|c|}{.118} \\
\hline
\end{tabular}

$\mathrm{f}^{2}: .02$ (small), .15 (medium), .35 (large)

족과 사회적 만족을 증가시키고 가맹본부에 대한 가맹점의 충성도를 제고 함으로써 프랜차이즈 시스템에서 가맹본부의 사회적 책임 활동에 대한 필요성과 중요성을 인식시키고, 가 맹본부와 가맹점 간의 상생하는 방안을 제시하고자 하였다.

본 연구의 학문적 시사점은 프랜차이즈 가맹점의 경제적 만족과 사회적 만족의 선행요인을 가맹본부의 경제적 책임 활동과 박애주의적 책임 활동으로 파악하였고, 결과적으로 이러한 요인이 가맹점의 충성도로 전이될 수 있는지를 보여 주었다는데 의의가 있다. 기존 연구에서는 기업의 사회적 책 임 활동이 소비자의 저품에 대한 태도, 기업 이미지, 명성, 만족 및 충성도와의 관계를 파악하였거나 개인 단위 차원인 내부 구성원의 조직 신뢰, 조직 동일시와 충성도와 같은 변 인들에 대한 영향 관계를 파악 했다면, 본 연구는 집단 단위 차원의 마케팅 대상인 가맹본부와 가맹점간의 관계마케팅 차원에서 가맹점의 지각된 가맹본부의 사회적 책임 활동과 가맹점의 충성도와의 관계를 실증 분 석하였다는 점에서 학 문적 시사점을 제시할 수 있다.

프랜차이즈 가맹점의 지각된 가맹본부의 사회적 책임 활 동에 대한 영향력을 실증분 석을 토대로 실 무적 시사점을 제 시하면 다음과 같다.

첫째, 경제적 책임 활동은 경제적 만족과 사회적 만족에 통계적으로 유의한 정 $(+)$ 의 영향을 미치는 것으로 나타났다. 이것은 가맹본부가 지속적인 제 품연구개발을 통한 상 품 구 색 다양화와 품질 개선, 그로 인한 매출액 증가, 가맹점의 운영비용 절감을 위한 효율적인 운영시스템 지원, 그리고 고 객 수를 늘리기 위한 효과적인 마케팅 활동 등의 경제적 책 임을 다한다고 가맹점이 지각할 때 가맹본부에 대한 경제적 만족은 증가한다고 판단할 수 있다. 또한, 가맹본부의 마케 팅 목표와 전략에 대한 공유, 고객 또는 가맹점의 컴플레인 을 신속하게 해결하기 위한 절차 수 립, 그리고 기업 이미지 제고를 위한 고 객 만족 정책을 전개할 때 가맹점은 사회적 만족이 증가한다고 판단할 수 있다. 가맹본부의 경제적 책임 활동은 가맹점에게 직접적인 영향을 미 친다. 이는 가맹본부 가 경제적 책임을 다하여 가맹점의 수 익이 증대될 때 비즈 니스적인 만족인 경제적 만족은 증대되고, 그 과정에서 공생 관계인 가맹본부와 가맹점간의 대인간 사회적 만족도 증가 한다고 판단할 수 있다. 따라서 가맹본부는 가맹점의 수 익향
상을 위한 지속적인 제 품연구개발과 마케팅 활동, 그리고 효 율적인 운영시스템을 적 극적으로 지원해야 할 것이고, 그 과 정에서 상호 존중하는 대인간 우호적인 커뮤니케이션 문화 를 정착시킬 필요가 있다고 사료된다.

둘째, 박애주의적 책임 활동은 사회적 만족에 통계적으로 유의한 정 $(+)$ 의 영향을 미치는 것으로 나타났다. 이러한 결 과는 외부 이해관계자들의 공 익을 목적으로 하는 박애주의 적 책임 활동을 신호이론(signal theory)의 관점에서 보면, 외부 이해 관계자인 가맹점은 박애주의적 책임 활동을 수행 하는 가맹본부에 대해 공정하고 긍정적인 이미지가 높다고 긍정적인 평가를 추 론함으로써 가맹본부에 대한 자부심과 조직 동일시가 높아져 사회적 만족도가 높아진다고 사 료된 다.

셋째, 경제적 만족은 충성도에 통 계적으로 유의한 정 $(+)$ 의 영향을 미치고, 또한 사회적 만족도 충성도에 통 계적으로 유 의한 정 $(+)$ 의 영향을 미치는 것으로 나타났다. 이러한 결과 는 프랜차이즈 가맹점의 관계 만족은 가맹본부에 대한 충성 도를 향상해 예비 가맹점주에 대한 호의적인 추 천과 가맹 계 약 종 료 시 재계약을 체결 함으로써 가맹본부와의 상호발전 을 추구하기 위해 안정적인 거래 관계를 지속적으로 할 수 있다는 것을 의미한다.

본 연구는 프랜차이즈 가맹점(서울 소재) 직원들을 연구 대상으로 프랜차이즈 가맹점의 지각된 가맹본부의 경제적 책임 활동과 박애주의적 책임 활동, 경제적 만족, 사회적 만 족, 그리고 충성도 간의 영향 관계를 실증적으로 검증하였으 며 이를 토대로 학문적, 실무적 시사점을 도출하였다. 그러 나 다음과 같은 연구 한 계점이 있다. 첫째, 연구대상이 특정 지역인 서울 소재 가맹점들로 한정되어 있어 대표성의 한계 로 전국 프랜차이즈 가맹점에 적용하기 어 렵다. 둘째, CSR 활동은 대부분 대기업 프랜차이즈 기업을 중심으로 진행되 고 있어 연구적 접근의 한 계가 있다. 마지막으로 본 연구는 프랜차이즈 가맹본부의 경제적 CSR 및 박애주의적 CSR과 가맹점의 충성도 간의 영향 관계를 연구하였으나 향 후 연구 에서는 프랜차이즈 가맹점의 정량적 데이터인 재계약률과 경영성과 등의 데이터를 토대로 프랜차이즈 기업의 사회적 책임 활동과 충성도의 관계를 분 석할 필요가 있다. 


\section{References}

Abdul-Muhmin, A. G. (2005). Instrumental and interpersonal determinants of relationship satisfaction and commitment in industrial markets. Journal of Business Research, 58(5), 619-628.

Anderson, J. C., \& Narus, J. A. (1990). A moderl of distributor firm and manufacturer firm working partnerships. Journal of Marketing, 54(1), 42-58.

Balmer, J. M., \& Greyser, S. A. (2006). Corporate marketing: integrating corporate identity, corporate branding, corporate image and corporate reputation. European Journal of Marketing, 40(7-8), 730-741.

Barone, M. J., Miyazaki, A. D., \& Tayler, K. A. (2000). The influence of cause-related marketing on consumer choice: Does one good turn deserve another?. Journal of the Academy of Marketing Science, 28(2), 248-262.

Bhattacharya, C. B., Rao, H., \& Glynn, M. A. (1995). Understandking the bond of identification: An investigation of its correlates among art museum members. Journal of Marketing, 59(4), 46-57.

Bhattacharya, C. B., \& Sen, S. (2003). Consumer-company identification: A framework for understanding consumers' relationships with companies. Journal of Marketing, 67(2), 76-88.

Bhattacharya, C. B., \& Sen, S. (2004). Doing better at doing good: When, why, and how consumers respond to corporate social initiatives. California Management Review, $4 \pi 1), 9-24$.

Biong, H. (1993). Satisfaction and loyalty to suppliers within the grocery trade. European Journal of Marketing, 277), 21-38.

Bolton, R. N., \& Drew, J. H. (1991). A multistage model of customers' assessments of service quality and value. Journal of Consumer Research, 174), 375-384.

Brammer, S., Millington, A., \& Rayton, B. (2007). The contribution of corporate social responsibility to organizational commitment. International Journal of Human Resource Management, 18(10), 1701-1719.

Brown, T. J., Barry, T. E., Dacin, P. A., \& Gunst, R. R.(2005). Spreading the word: Investigating antecedents of consumers' positive word-of-mouth intentions and behaviors in a retailing context. Journal of the Academy of Marketing Science, 33(2), 123-138.

Brown, T. J., \& Dacin, P. A. (1997). The company and the product: Corporate associations and consumer product responses. Journal of Marketing, 61(1), 6-84.

Bubb, P. L., \& Van Rest, D. J. (1973). Loyalty as a component of the industrial buying decision. Industrial Marketing Management, 3(1), 25-32.

Carroll, A. B. (1979). A three-dimensional conceptual model of corporate performance. Academy of Management Review, 4(4), 497-505.

Carroll, A. B. (1991). The pyramid of corporate social responsibility: Toward the moral management of organizational stakeholders. Business Horizons, 34(4), $39-48$.

Chin, W. W. (1998). The partial least squares approach to structural equation modeling. Modern Methods for Business Research, 295(2), 295-336.

Choi, B. K., Moon, H. K., \& Joo, Y. R. (2017). Review and future research rirection for csr perception in korea: Focus on employees' perceived csr. Korea Business Review, 46(5), 1247-1302.

Choi, W. Y., Lee, H. S., \& Hong, C. S. (2009). Corporate social responsibility and firm value: Focused on corporate contributions. Korean Management Review, 38(2), 407-432.

Coase, R. H. (1937). The nature of the firm. Economica, 4(16), 386-405.

Cohen, J. (1988). Statistical power analysis for the behavioral sciences. 2nd ed., NJ: Erlbaum.

Corson, J. J., Steiner, G. A., \& Meehan, R. C. (1974). Measuring business's social performance: The corporate social audit (No.39). Committee for Economic.

Crosby, L. A., Evans, K. R., \& Cowles, D. (1990). Relationship quality in services selling: An interpersonal influence perspective. Journal of Marketing, 54(3), 68-81.

Dwyer, F. R., \& Oh, S. (1987). Output sector munificence effects on the internal political economy of marketing channels. Journal of Marketing Research, 24(4), 347-358.

Dwyer, F. R., Schurr, P. H., \& Oh, S. (1987). Developing buyer-seller relationships. Journal of Marketing, 51(2), 11-27.

Falk, R. F., \& Miller, N. B. (1992). A primer for soft modeling. University of Akron Press.

Farooq, O., Payaud, M., Merunka, D., \& Valette-Florence, P. (2014). The impact of corporate social responsibility on organizational commitment: Exploring multiple mediation mechanisms. Journal of Business Ethics, 125(4), 563-580.

Foreh, M. R., \& Grier, S. (2003). When is honesty the best policy? The effect of stated company intent on consumer skepitcism. Journal of Consumer Psychology, 13(3), 349-356.

Fornell, C. (1992). A national customer satisfaction barometer: The swedish experience. Journal of Marketing, 561), 6-21.

Ganesan, S. (1994). Determinants of long-term orientation in buyer-seller relationships. Journal of Marketing, 58(2), 1-19.

Gassenheimer, J. B., \& Ramsey, R. (1994). The impact of dependence on dealer satisfaction: A comparison of reseller-supplier relationships. Journal of Retailing, 70(3), 253-266.

Gassenheimer, J. B., Baucus, D. B., \& Baucus, M. S. (1996). Cooperative arrangements among entrepreneurs: An analysis of opportunism and communication in franchise structures. Journal of Business Research, 36(1), $67-79$. 
Geyskens, I., Steenkamp, J. B. E., \& Kumar, N. (1999). A meta-analysis of satisfaction in marketing channel relationships. Journal of Marketing Research, 36(2), 223-238.

Geyskens, I., \& Steenkamp, J. B. E. (2000). Economic and social satisfaction: measurement and relevance to marketing channel relationships. Journal of Retailing, 76(1), 11-32.

Gruca, T. S., \& Rego, L. L. (2005). Customer satisfaction, cash flow, and shareholder value. Journal of Marketing, 69(3), 115-130.

Ha, H. Y., Lee, M. S., \& Janda, S. (2016). Effects of economic and social satisfaction on partner trust: an investigation of temporal carryover effects. European Journal of Marketing, 50(1/2), 100-123.

Hair, J. F., Ringle, C. M., \& Sarstedt, M. (2013). Partial least squares structural equation modeling: Rigorous applications, better results and higher acceptance. Long Range Planning, 46(1), 1-12.

Hair Jr, J. F., Hult, G. T. M., Ringle, C., \& Sarstedt, M. (2016). A primer on partial least squares structural equation modeling (PLS-SEM). Sage Publications.

Han, K. C., \& Yu, J. P. (2010). A study on the effects of franchisor's marketing mix on relationship quality and interrelations among commitment and long-term orientation in the foodservice industry. Journal of Product Research, 28(6), 29-41.

Han, S. L., \& Lee, J. W. (2016). Effects of corporate social responsibility on factors affecting development of relationship, trust and long-term orientation in b2b market. Korea Business Review, 45(3), 869-900.

Hansen, S. D., Dunford, B.B., Boss, A. D., Boss, R. W., \& Angermeier, I. (2011). Corporate social responsibility and the benefits of employee trust: A cross-disciplinary perspective. Journal of Business Ethics, 102(1), 29-45.

Hess, D., Rogovsky, N., \& Dunfee, T. W. (2002). The next wave of corporate community involvement: Corporate social initiatives. California Management Review, 44(2), 110-125.

Hoffman, K. D., \& Bateson, J. E. (2011). Services marketing. South-Western/Cengange Learning.

Homburg, C., Koschate, N., \& Hoyer, W. D. (2005). Do satisfied customers really pay more? A study of the relationship between customer satisfaction and willingness to pay. Journal of Marketing, 69(2), 84-96.

Hulland, J. (1999). Use of partial least squares (PLS) in strategic management research: A review of four recent studies. Strategic Management Journal, 20(2), 195-204.

Huo, Y. H. (2012). Franchise system theory:Its evolution and application toward restaurant franchise. Korean journal of Hospitality \& Tourism, 21(2), 165-187.

Hur, K. S., Ko, S. M., \& Byun, J. W. (2014). The Effects of csr on the organizational esteem, efficacy, identification, and customer orientation for hotel employees. International Journal of Tourism Management and Sciences, 29(1),
97-118.

Hur, K. S., \& Choi, S. R. (2014). Effects of korean franchise bakery's corporate social responsibility(csr) authenticity on brand trust and brand loyalty. Journal of Foodservice Management Society of Korea, 176), 7-28.

Hur, S. B., Chang, J. Y., \& Lee, J. G. (2018). The Impact of foodservice franchisee's perceived justice on cohesiveness, relationship satisfaction, and franchisee's long-term orientation. Korean Journal of Franchise Management, 9(3), 31-43.

Jones, D. A. (2010). Does serving the community also serve the company? Using organizational identification and social exchange theories to understand employee responses to a volunteerism programme. Journal of Occupational and Organizational Psychology, 83(4), 857-878.

Kang, I. H., Kim, Y. K., \& Kim, S. O. (2006). Relationship characteristics and recontracting intention in Food service franchise system. Korean Journal of Hospitality \& Tourism, 15(2), 223-240.

KFI. (2018). 2018 Social value report for major companies. KFI Issue Report, The federation of korean industries.

Kim, H. S. (2018). Impacts of economic satisfaction and social satisfaction of franchisee on commitment and loyalty to franchisor. Korean Journal of Franchise Management, 94), 21-31.

Kim, J. H. (2007). The impact of support and dissensus on economic satisfaction, conflict, trust, and commitment in the franchise system. Journal of Distribution Research, 12(1), 33-63.

Kim, K. Y., \& Cho, S. B. (2014). The effect of csr on consumer perception and behavioral intention: Focus on leading deluxe tourist hotel in seoul. International Journal of Tourism and Hospitality Research, 28(2), 65-73.

Lee, I, S., \& Choi, J. S. (2010). Impact of hotelier's csr recognition on role behavior and organizational citizenship behaviors. International Journal of Tourism and Hospitality Research, 24(4), 321-336.

Lee, K. H., An, S. H., \& Lee, Y. K. (2010). The impact of csr on organizational citizenship behavior in franchise industry: Mediating role of organizational trust. Journal of Foodservice Management, 13(4), 297-321.

Lee, Y. K., Lee, K. H., \& Li, D. X. (2012). The impact of CSR on relationship quality and relationship outcomes: A perspective of service employees. International Journal of Hospitality Management, 31(3), 745-756.

Lee, H., Park, T., Moon, H. K., Yang, Y., \& Kim, C. (2009). Corporate philanthropy, attitude towards corporations, and purchase intentions: A south korea study. Journal of Business Research, 62(10), 939-946.

Lewis, M. C., \& Lambert, D. M. (1991). A model of channel member performance, dependence, and satisfaction. Journal of Retailing, 67(2), 205-225.

Lim, H. C. (2015). The mediator effect of supporting service satisfaction between the relation of management 
performance and supporting service for small business people. International Journal of Tourism Management and Sciences, 307), 319-338.

Lim, H. C., \& Kwon, H. J. (2017). The effect of corporate social responsibility activity on brand image, management performance and recontracting intention in foodservice industry. Tourism Research, 42(1), 85-107.

Lin, C. P. (2010). Modeling corporate citizenship, organizational trust, and work engagement based on attachment theory. Journal of Business Ethics, 94(4), 517-531.

Luo, X., \& Bhattacharya, C. B. (2006). Corporate social responsibiltiy, customer satisfaction, and market value. Journal of Marketing, 70(4), 1-18.

Maignan, I., Ferrell, O. C., \& Hult, G. T. M. (1999). Corporate citizenship: Cultural antecedents and business benefits. Journal of the Academy of Marketing Science, 27(4), 455-469.

Maignan, I., \& Ferrell, O. C. (2001). Corporate citizenship as a marketing instrument-concepts, evidence and research directions. European journal of Marketing, 35(3/4), 457-484.

Ministry of Trade, Industry and Energy. (2019). 2018 Franchise Industry Survey, Retrieved from http://www.korea.kr/news/pressReleaseView.do?newsld=156 325456\&call_from=seoul_paper

Mittal, V., Anderson, E. W., Sayrak, A., \& Tadikamalla, P. (2005). Dual emphasis and the long-term financial impact of customer satisfaction. Marketing Science, 24(4), 544-555.

Mohr, L. A., \& Webb, D. J. (2005). The effects of corporate social responsibility and price on consumer responses. Journal of Consumer Affairs, 39(1), 121-147.

Oliver, R. L. (1980). A cognitive model of the antecedents and consequences of satisfaction decisions. Journal of Marketing Research, 174), 460-469.

Ostlund, L. E. (1977). Attitudes of managers toward corporate social responsibility. California Management Review, 19(10), 939-946.

Park, E., A., Kim, E.-J., Jeon, S.-K., \& Lee, Y.-K. (2016). The effect of customer experiential value on action flow, performance satisfaction, and loyalty in performing arts market. Journal of Culture Industry, 16(4), 133-145.

Park, J. C., Lee, J. K.,\& Lim, S. Y. (2015). The reinvestigating of psychological mechanism in the 'csr-customers' loyalty' relation: Focused on mediating of gratitude, trust, satisfaction, and commitment. Korean NPO review, 14(2), 73-85.

Park, S. Y., Koo, D. M., \& Kang, B. H. (2012). Consumers' attributions, perception, and responses on csr activities. Korea Business Review, 41(2), 173-200.

Peterson, D. K. (2004). The relationship between perceptions of corporate citizenship and organizational commitment. Business \& Society, 43(3), 296-319.

Pivato, S., Misani, N., \& Tencati, A. (2008). The impact of corporate social responsibility on consumer trust: the case of organic food. Business Ethics: A European Review, 171), 3-12.

Scheer, L. K., \& Stern, L. W. (1992). The effect of influence type and performance outcomes on attitude toward the influencer. Journal of Marketing Research, 29(1), 128-142.

Sen, S., \& Bhattacharya, C. B. (2001). Does doing good always lead to doing better? Consumer reactions to corporate social responsibility. Journal of Marketing Research, 38(2), 225-243.

Shin, C. H., Kim, Y. S., \& Kim, C. M. (2000). An empirical analysis on the influence of re-contract intention in a franchise business. Journal of Marketing Management Research, 5(2), 79-101.

Stites, J. P., \& Michael, J. H. (2011). Organizational commitment in manufacturing employees: Relationships with corporate social performance. Business \& Society, 50(1), 50-70.

Szymanski, D. M., \& Henard, D. H. (2001). Customer satisfaction: A meta-analysis of the empirical evidence. Journal of the academy of marketing science, 29(1),16-35.

Tenenhaus, M. Vinzi, V. E., Chatelin, Y. M., \& Lauro, C. (2005). PLS path modeling. Computational Statistics \& Data Analysis, 48(1), 159-205.

The Federation of Korean Industries. (2018). 2018 Social Value Report of Major Companies. Issue Paper.

Turker, D. (2009). How corporate social responsibility influences organizational commitment. Journal of Business Ethics, 89(2), 189-204.

Valentine, S., \& Fleischman, G. (2008). Ethics programs, perceived corpprate social responsibility and job satisfaction. Journal of Business Ethics, 772), 159-172.

Vinzi, V. E., Trinchera, L., \& Amato, S. (2010). PLS path modeling: From foundations to recent developments and open issues for model assessment and improvement. Handbook of Partial Least Squares (47-82), Springer Berlin Heidelberg.

Vlachos, P. A., Theotokis, A., \& Panagopoulos, N. G.(2010). Sales force reactions to corporate social responsibility: Attributions, outcomes, and the mediating role of organizational trust. Industrial Marketing Management, 397), 1207-1218.

Weber, M. (2008). The business case for corporate social responsibility: A company-level measurement approach for csr. European Management Journal, 26(4), 247-261.

Wi, P. R. (2018). Focus on economic power as chaebol: The dynamic changes and policy implications. Economic Reform Report, 1-34, ERRI.

Yu, J. P., \& Han, K. C. (2009). A study on the impacts of power sources, influence, economic \& non-economic satisfaction, and trust on long-term orientation between manufacturers and retailers: Focused on local discount stores. Korean Journal of Business Administration, 22(1), $1-26$. 